\title{
Pulmonary vein isolation by the helical approach
}

\author{
Márcio Galindo Kiuchi ${ }^{1}$, Guilherme Miglioli Lobato ${ }^{2}$ and Shaojie Chen ${ }^{3}$ \\ ${ }^{1}$ Artificial Cardiac Stimulation Division, Department of Medicine, Hospital e Clínica São Gonçalo, São Gonçalo, RJ, Brazil \\ ${ }^{2}$ Anesthesiology Division, Department of Medicine, Hospital e Clínica São Gonçalo, São Gonçalo, RJ, Brazil \\ ${ }^{3}$ Department of Cardiology, Shanghai First People's Hospital, Shanghai Jiao Tong University School of Medicine, Shanghai, China
}

\section{Case report}

The perfect line of attack for the management of AF is rhythm control, but this is sometimes very hard to accomplish [1]. For such actions, complete isolation of all pulmonary veins (PVI) is currently widely accepted as the best endpoint. The recommendations of the European Society of Cardiology (ESC) (Guidelines for the management of atrial fibrillation: the Task Force for the Management of Atrial Fibrillation of the European Society of Cardiology (ESC) [1]. For the individual patient with symptomatic AF, there must be sufficient potential benefit to justify a complex ablation procedure associated with possibly severe complications. Operator experience is an important consideration when considering ablation as a treatment option. The studies cited in support of the recommendations have been almost exclusively performed by highly experienced operators and expert staff working in specialized institutions, but in clinical practice, more junior and less experienced operators may be involved in many institutions. Catheter ablation is usually undertaken in patients with symptomatic paroxysmal AF that is resistant to at least one antiarrhythmic drug. Catheter ablation for paroxysmal AF should be considered in symptomatic patients who have previously failed a trial of antiarrhythmic medication (Class IIa, Level A). Ablation of persistent symptomatic AF that is refractory to antiarrhythmic therapy should be considered a treatment option (Class IIa, Level B).

In this case, we presented a case of a male patient, 69 years old, with hypertension, type 2 Diabetes Mellitus, having already been previously stroke, cholecystectomy previously, and treated for prostate cancer, without coronary artery disease, currently presenting the following symptoms: pre-syncope episodes associated with sustained irregular palpitation tachycardia and dyspnea on the usual efforts. The Duplex scan of carotid and vertebral was normal. The transthoracic echocardiogram presented normal systolic function with left ventricular ejection fraction measured by Simpson's method $=80 \%$, and left atrium diameter $=44 \mathrm{~mm}$, with the rest of the measurements normal, as well as, the resting myocardial scintigraphy and with drug use did not demonstrate ischemia and/or fibrosis. Angiography coronary arteries presented normally. The 24-hour ambulatory blood pressure measurements $(\mathrm{ABPM})$ showed: mean $\mathrm{ABPM}=136 / 79$ $\mathrm{mmHg}$, wakeful $\mathrm{ABPM}=138 / 90 \mathrm{mmHg}$, sleep ABPM $=131 / 78 \mathrm{mmHg}$ and maximum systolic awake ABPM $=194 \mathrm{mmHg}$. The 24-hourHolter monitoring demonstrated minimum - average - maximum heart rate (HR): $49-69-117 \mathrm{bpm}$, presenting sinus rhythm alternated with paroxysmal atrial fibrillation (AF), 13,136 atrial ectopic beats, and the major PR interval measuring $280 \mathrm{~ms}$. The patient was in use of losartan $100 \mathrm{mg}$ daily, amlodipine $10 \mathrm{mg}$ daily, hydrochlorothiazide $25 \mathrm{mg}$ daily, propafenone hydrochloride $300 \mathrm{mg}$ three times daily and dabigatran $150 \mathrm{mg}$ two times daily, as well as, the other oral hypoglycemic drugs (the ethics committee composed by Paola Baars Gomes Moises, Luis Marcelo Rodrigues Paz, Humberto Cesar Tinoco e Jonny Shogo Takahashi, approved the execution of the case). Informed consent was signed by the patient.

The electrophysiological study demonstrated a distal conduction block (HV interval $=96 \mathrm{~ms})$, already having dual chamber pacing implantation indicator in a second time. The patient was submitted to general anesthesia by an anesthesiologist, and $2 \mathrm{~g}$ of cefazolin was administered intravenously. He presented sinus rhythm before the procedure begins. Under fluoroscopic vision, three right femoral vein punctures were performed, with 1 sheath $6 \mathrm{~F}$, one $8 \mathrm{~F}$ and another 12F. Through the sheath $12 \mathrm{~F}$, the Agilis ${ }^{\text {rix }}$ NxT Steerable Introducer (St. Jude Medical, USA) was inserted, and the sheath $8 \mathrm{~F}$ was replaced by the long sheath Fast-Cath ${ }^{n x}$ Transseptal Guiding Introducers SL-0 (St. Jude Medical, USA). Through the sheath $6 \mathrm{~F}$ a diagnostic decapolar catheter was inserted into the coronary sinus (CS). We performed two transeptal punctures using a 71 and $98 \mathrm{~cm}$ BRK $^{\mathrm{mi}}$ Transeptal Needles (St. Jude Medical, USA), respectively, and the right femoral artery was punctured, being inserted an $8 \mathrm{~F}$ sheath to monitor invasive blood pressure. Electro-surgical plate and EnSite ${ }^{\mathrm{m}}$ Velocity $^{\text {mim }}$ Cardiac Mapping System (St. Jude Medical, USA) electrode for electro-anatomical mapping were positioned on the patient. Right heart chambers catheterization were performed, and left chambers catheterization were also performed after double transeptal punctures, with the following catheter positions:

- A decapolar dirigible catheter was positioned within the CS;

- A decapolar dirigible circular catheter, in pulmonary veins and left atrium, alternately;

- Four EnligHTN ${ }^{\mathrm{m}}$ catheters (St. Jude Medical, USA) into the pulmonary veins, alternately (Figure $1 \mathrm{~A}, \mathrm{~B}, \mathrm{C}$, and D);

- After the withdrawal of the EnligHTN ${ }^{\mathrm{wx}}$ (St. Jude Medical, USA), we replaced it for the TactiCath ${ }^{\text {Tn }}$ Quartz Contact Force Ablation Catheter (St. Jude Medical, USA), in the left atrium and pulmonary veins, alternately.

The long sheaths in the left atrium were maintained continuously irrigated with heparinized saline. Infusion of heparin was performed by an infusion pump, keeping the coagulation activated time $>300$

Correspondence to: Márcio Galindo Kiuchi, Rua Cel. Moreira César, 138 Centro, São Gonçalo - Rio de Janeiro - Brazil. ZIP-CODE: 24440-400.Tel and Fax: +55 (21) 26047744

Received: March 26, 2017; Accepted: April 26, 2017; Published: April 29, 2017 


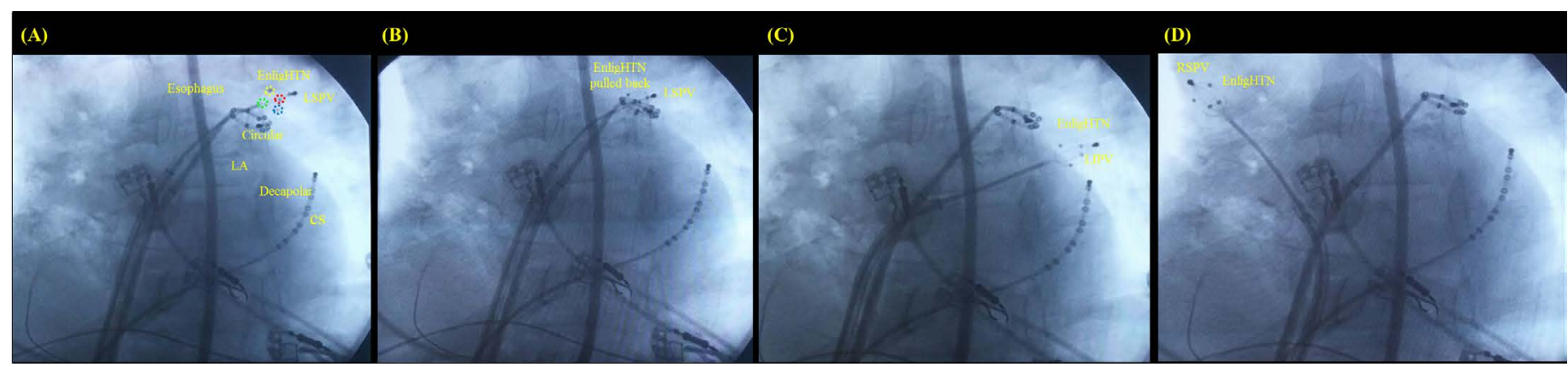

Figure 1. (A) EnligHTN ${ }^{\mathrm{TM}}$ catheter open into the LSPV, (B) pulled back for new helical ablation spots, (C) into the LIPV, and (D) into the RSPV. Circular, decapolar dirigible circular catheter; CS, coronary sinus; Decapolar, decapolar dirigible catheter; EnligHTNTM catheter poles demonstrated in blue, green, red and yellow; LA, left atrium; LIPV, left inferior pulmonary vein; LSPV, left superior pulmonary vein; RS, right superior pulmonary vein.

seconds. The esophagus remained in the center retro-atrial midline. The electro-anatomical map reconstruction of the left atrium and pulmonary veins by the EnSite ${ }^{\mathrm{mm}}$ Velocity ${ }^{\mathrm{mm}}$ Cardiac Mapping System (St. Jude Medical, USA) was performed, and helical applications were done in system manner "quartet" with the construction of three low-power propellers inside each pulmonary vein by the catheter EnligHTN ${ }^{\mathrm{m}}$ being used one unit for each pulmonary vein, according to the size of the vein (total of four pulmonary veins), with a power of $5 \mathrm{~W}$ and maximum temperature of $70^{\circ} \mathrm{C}$, during 60 seconds, with reduction and modification of the pulmonary vein electrical signals displayed in the decapolar circular catheter. To eliminate the few remaining electrical potentials we used the TactiCath ${ }^{\mathrm{T}}$ Quartz Contact Force Ablation Catheter (St. Jude Medical, USA), as shown in Figure. Radiofrequency applications were made in the antrum of the pulmonary veins of the left atrium, using the power of $35 \mathrm{~W}$ and maximum temperature of $42^{\circ} \mathrm{C}$. Atrial and pulmonary intra-vein stimulation to check pulmonary vein inlet and outlet blockade confirmed the isolation of pulmonary veins (Figure 2). New decrement atrial electrical stimulation at continuous cycles of 350 to $200 \mathrm{ppm}$ did not induce sustained new arrhythmias, maintaining sinus rhythm. The total procedure time was approximately 30 minutes.

After 48 hours the patient was discharged, using the same medications; the symptoms were no longer present; no AF episodes

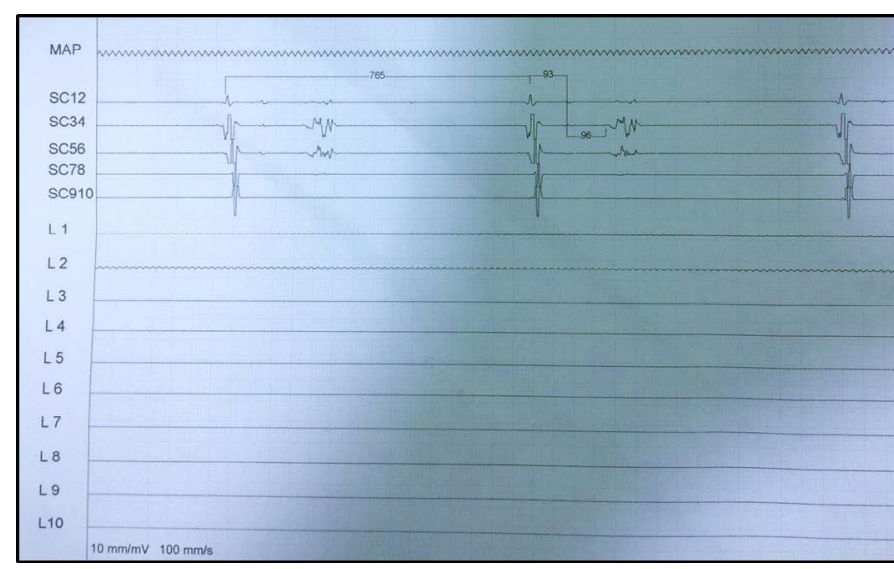

Figure 2. Left superior pulmonary vein isolated. The electrophysiological study demonstrated a distal conduction block ( $\mathrm{HV}$ interval $=96 \mathrm{~ms})$.

appeared during this period. Until the present time of follow up (1 month), the patient remained asymptomatic, without AF.

\section{References}

1. Camm AJ, Kirchhof P, Lip GY, Schotten U, Savelieva I, et al. (2010). Guidelines for the management of atrial fibrillation: the Task Force for the Management of Atria Fibrillation of the European Society of Cardiology (ESC) Eur Heart J 31: 2369-429.

Copyright: $\odot 2017$ Kiuchi MG. This is an open-access article distributed under the terms of the Creative Commons Attribution License, which permits unrestricted use, distribution, and reproduction in any medium, provided the original author and source are credited. 